\title{
Near-Death Utopias: Now or Later?
}

\author{
Kathy Charmaz, Ph.D. \\ Sonoma State University
}

\begin{abstract}
By viewing near-death experiences (NDEs) in the context of the quest for an ideal society, Kellehear offered hope for positive social change and insight into the social, rather than purely personal, meanings of the NDE. However, his approach raised issues of the interpretive research process generally. As with any research, near-death studies are influenced by investigators' questions, interests, and assumptions. Despite the reasoning behind Kellehear's position, he grounded his analysis not in the data, but rather in his typology of ideal societies. I suggest we look first for indications of ideal social order in near-death narratives, and only later compare them with types of utopias.
\end{abstract}

Allan Kellehear developed a suggestive theme in the near-death literature by relating these experiences to a quest for ideal or utopian society. His knowledge of both utopian thought and near-death experiences (NDEs) is thorough and erudite. Looking at NDEs through the prism of the quest for an ideal society, his view was both optimistic and didactic. By viewing these near-death narratives as imbedded in a pursuit for the ideal society, Kellehear offered hope for positive social change and betterment of the human condition. Further, Kellehear viewed these narratives as offering ideas about the nature of society, therefore as instructive for social meanings rather than purely personal illumination or spiritual knowledge. These are intriguing ideas; but do they work?

Before addressing this question, I wish to place my remarks in the larger context of doing qualitative research. A close study of Kel-

Kathy Charmaz, Ph.D., is Chairperson of the Department of Sociology at Sonoma State University. Reprint requests should be addressed to Dr. Charmaz at the Department of Sociology, Sonoma State University, 1801 East Cotati Avenue, Rohnert Park, CA 94928. 
lehear's analysis can raise a series of issues directly pertaining to researching NDEs particularly and to dilemmas and issues in interpretive research methods more generally. The ambiguity surrounding NDEs as well as the blurred distinctions between these and related experiences makes defining the parameters of study difficult (Zaleski, 1987). Further, the methods of learning about NDEs lie within the frontier between traditional science and spiritual visions, making researching them seem fraught with methodological and philosophical hazards. Those who study these experiences may themselves hold, and likely are judged by, the traditional canons of positivistic science. Certainly, the study of near-death experiences has elicited debates and doubts about both the nature of the experience and the scientific legitimacy of the research process itself.

Kellehear's analysis is a welcome break from zealous examinations of the veracity of near-death narratives and from painstaking questions about how the investigators' interests and style of questioning could have contaminated, influenced, or produced the narratives. Whether interviewers prod their respondents and pull information from them or the stories simply tumble out without pause, the stories are, at least in part, an artifact of the research process and the specific interview situation. But that doesn't necessarily make them less interesting or significant. Like any other research that relies on responses generated by questions, to some extent, these accounts are a product of an interaction process bounded by time, culture, and conventions of discourse. Similarly, like any other research, the final products are shaped by the investigator's guiding research questions, methodological skill and interests, personal intuitions, theoretical acumen, philosophical assumptions, and analytic proclivities.

Placing this kind of research squarely into the canons of positivism trivializes it. Nonetheless, tensions remain between positivistic goals of attempting to define the objects of study beforehand, describing them accurately, and ordering the data according to their "inherent" characteristics and phenomenological goals to get inside the experience, to capture its essence, and to give voice to those who have it. All this is further complicated by the postmodernist critiques of rendering ethnographic data and questioning the authoritative voice imposed upon the data by the researcher (Atkinson, 1990; Clifford and Marcus, 1986; Marcus and Fischer, 1986; Schneider, 1991).

To what extent do near-death researchers impose their voice and their ideas on their data? To what extent might they distill and reify conclusions from the fleeting images and fragmented narratives that they collect? Kellehear's analysis offered an interpretive rendering of 
transcendent experiences; but might he not have veered in the direction of over-interpretation? However useful his claims of utopian societies are because they move the literature away from dreary debates about veracity, might they not have been overdrawn? Perhaps. Kellehear did move the discussion beyond descriptive types into the realm of meaning and ideas. Moreover, his interpretations may have rested on solid evidence and careful reasoning. However, Kellehear did not ground his analysis systematically in his data, which I gather here primarily consisted of a secondary analysis of near-death research. Nor did he take his reader through the analytic steps that he employed. Rather, he reviewed the social and political characteristics of types of ideal societies and their respective applicability to near-death experiences. I propose doing just the opposite. Why not examine the neardeath narratives first for indications of ideal social order, not merely fleeting images, including those of social and political life? After providing solid evidence of ideal social orders, one could distinguish between those narratives that reveal them, those that offer fleeting images, and those that provide neither. Further, why not start with the implicit and explicit meanings within the narratives themselves rather than directly applying a typology of ideal societies upon them? In doing so, the researcher could give greater voice to the authors of the narratives rather than assuming authority over them. After presenting, developing, and analyzing their stories, the researcher could then compare them with ideal types of utopias.

Kellehear did draw upon descriptions of the narratives Craig Lundahl (1981-82) collected for developing his ideas about transcendent societies that go beyond transcendent visions or images. Lundahl pointed out that his nine selected accounts were unusual in the length, and consequently the detail, of the reported near-death experiences. That typical brevity, which Kellehear noted, made the analytic jump between transcendent visions and utopian societies problematic. Although Lundahl's narratives may have been more complete than most, Kellehear must have found substantial evidence of similar themes in the other accounts that he mentioned. It would have helped if he had traced these connections explicitly for his reader; we could then better assess his evidence and his reasoning.

What these experiences might mean and how to render the subsequent stories analytically are both intriguing and perplexing issues, sometimes to people who have them as well as to their research analysts. The stories are recounted narratives written in memory and retold as significant events. As such, they are imbedded in consciousness and shape meaning - whether related as given, as emergent, or as 
ambiguous (Charmaz, 1991). With any retold story, the views of the past are selective, told from the vantagepoint of the present. Hence, what happened between past and present colors and shapes the interpretations of the past. Conversely, images from the past shade present experience. If as social beings we draw upon socially acquired knowledge to understand our experience, it is not surprising that people relate transcendent visions to familiar objects and ideals. Emile Durkheim (1913) pointed out long ago that human beings took the idealized structure of their own society as the structure of heaven.

To me, the move from transcendent utopian visions in the narratives to relatively well-articulated utopian societies seems somewhat overdrawn and forced. Of course, Kellehear may have intended to overstate his case to make his point. However, in its present form, this comparison of images of society found in near-death narratives with utopian societies takes a visionary image and reifies it into a society. Although instructive as one way of viewing these experiences, I do not find Kellehear's argument to be wholly convincing as he articulated it at this time. Nonetheless, the fresh view he offered in looking at these narratives is welcome. Further, the analytic agenda I have laid out surely exceeds what could reasonably be accomplished in one short article. But I hope Kellehear pursues it. In the meantime, he has provided us with a provocative and creative beginning. And to quote Kellehear's ending remark: "That may just be enough."

\section{References}

Atkinson, P. (1990). The ethnographic imagination: Textual constructions of reality. London, England: Routledge.

Charmaz, K. (1991). Good days, bad days: The self in chronic illness and time. New Brunswick, NJ: Rutgers University Press.

Clifford, J., and Marcus, G.E. (1986). Writing culture: The poetics and politics of ethnography. Berkeley, CA: University of California Press.

Durkheim, E. (1913). The elementary forms of the religious life. Glencoe, IL: The Free Press.

Lundahl, C.R. (1981-82). The perceived otherworld in Mormon near-death experiences: A social and physical description. Omega, 12, 319-327.

Marcus, G.E., and Fischer, M.M.J. (1986). Anthropology as cultural critique. Chicago, IL: University of Chicago Press.

Schneider, J.W. (1991). Troubles with textual authority in sociology. Symbolic Interaction, 37, 295-319.

Zaleski, C. (1987). Otherworld journeys: Accounts of near-death experience in medieval and modern times. New York, NY: Oxford University Press. 